\title{
Automatic manhole extraction from MMS data to update basemaps.
}

\begin{abstract}
Basemaps are the main resource used in urban planning, building and infrastructure asset management. Therefore, they must be accurate and up to date to better serve citizens, contractors, property owners and town planning departments. Traditionally, they have been updated by aerial photogrammetry, but this is not always possible and alternatives need to be sought. In such cases, a useful option for large scales is the mobile mapping system (MMS). However, automatic extraction from MMS point clouds is limited by the complexity of the urban environment. Therefore, the influence of the urban pattern is analysed in three zones with varied urban characteristics: areas with high buildings, open areas, and areas with a low level of urbanization. In these areas, the capture and automatic extraction of 3D urban elements is performed using commercial software, which is useful for some elements but not for manholes. The objective of this study is to establish a methodology for extracting manholes automatically and completing hidden buildings' corners, in order to update urban basemaps. Shape and intensity are the main detection parameters for manholes, whereas additional information from satellite image Quickbird is used to complete the buildings. The worst rate of detection for all the extracted urban elements was found in areas of high buildings. Finally, the article analyses the computing cost for manhole extraction, and the economic cost and time consume of the entire process, including the proposed methodology using an MMS point cloud and the traditional survey in this case.
\end{abstract}

Keywords: mobile mapping, LiDAR, basemap updating, geospatial data processing, municipalities, feature extraction, vectorization, point cloud classification

\section{INTRODUCTION}

Local and regional governments rely on basemaps for their essential activities. Hence, it is vital to ensure that basemaps are accurate and up to date. A comprehensive basemap with integrated geographic information can support and facilitate decisions about a city's urban planning, building, emergency services, mobility and infrastructure asset management.

Building and infrastructure asset management plays a significant role in any infrastructure project due to the extensive use of spatial data and map applications. These applications serve citizens in their everyday activities such as finding and reaching destinations via an easy, short route. In addition, city managers use map applications to plan their daily activities, such as waste collection, irrigation and lighting, at a time when the number of smart cities is increasing worldwide. To keep these applications useful, spatial data must be updated frequently to detect changes.

Recently, the term Geodesign has been applied to environmental planning and design $[1,2]$. Geodesign is one in a long line of technological developments that have generated tools and techniques for existing activities and disciplines. Applications would be complex projects involving multidisciplinary groups. However, one of the fundamental elements in these projects is a "basemap" on which the rest of the elements are designed [3].

Accurate, up-to-date knowledge of geometry is important in the analysis of urban changes and in studies of landscape and urban planning applications. An example can be found in some studies $[4,5]$ that analysed urban development according to 2D maps of different periods. However, these studies would be more complete, detailed and accurate if they were updated with 3D models in urban environments $[6,7]$ since the available information considers additional characteristics such as the height of the elements, which is useful for view analysis. 
Map updating consists of three main steps: i) comparing a new data source with the existing basemap, ii) identifying changes and updating them in the database and iii) verifying the logical consistency between the updated and the old version [8].

Effective, sustainable urban planning development requires advanced technologies to obtain and collect upto-date geospatial data. Geomatics techniques that are used to gather spatial information and create maps include remote sensing (such as satellite images and LiDAR), GNSS (Global Navigation Satellite Systems) and photogrammetry [3, 9-11]. The Mobile Mapping System (MMS), also called Mobile LiDAR System (MLS) or Mobile Lidar Mapping System (MLMS), that integrates some of these techniques could currently be considered an effective data source that provides 3D data on urban landscapes and their changes over time. The availability of such data is very important to generate up-to-date maps, and for the development and applications of urban and landscape planning, ecological engineering analysis, change detection, design and management studies.

The main drawback of massive capture systems, photogrammetry or MMS is data management, and how to extract "features" from a 3D point cloud with millions of points and their coordinates, colour and intensity values. Some commercial software allows us to extract part of urban elements correctly with acceptable accuracy. Most of the algorithms that are used are drawn from a previous classification based on the trajectory [12-14] and geometric characteristics of the elements [13, 15-18] or they take advantage of the spectral answer [19]. Thus, elements such as trees, light poles and traffic signals can be detected. Despite the available commercial software are highly effective in most feature extraction, some aspects are not completely solved. A clear example is the limitations for manhole extraction processes, which require manual work or extra work. All this motivated us to seek a method to resolve this issue. We propose a method for detecting manholes that uses both characteristics from a point cloud: the geometry and the intensity of the return signal.

Other elements that cannot be extracted correctly from the point cloud are all the corner buildings. In this case, the problem is not the extraction algorithm but a lack of points, since points are hidden by other elements. In this case, we propose the use of complementary information from a remote sensing satellite. However, an adjustment must be made because of the varying accuracy of the sources of geographic data. We analyse the results of two adjustment methods, to choose the most suitable for this purpose.

The main goal of this study is to present a new methodology for detecting manholes and complete buildings and extracting urban features, roads and infrastructure assets from a 3D point cloud registered using an MMS, to update a basemap. We evaluate the effort required by this methodology in terms of computational and financial cost, and human equipment improvement at a test site. The methodology can be used to keep a basemap up to date and thus provide accurate spatial data for urban planning, geodesign, construction of buildings and infrastructure, asset management and property. Moreover, a basemap is fundamental in autonomous driving applications. The paper is organized as follows: Section 2 summarizes previous studies related to the feature of automatic extraction. Section 3 details the proposed method for extracting manholes and completing the hidden corners of buildings, and the analysis of parameters for other street elements. Section 4 describes a case study in an urban area of Abu Dhabi Emirate with flight restrictions due to proximity to the border with other countries. Finally, the results and conclusions are given in Sections 4 and 5 , respectively.

\section{PREVIOUS WORKS}

As mentioned above, regional development plans require the use of accurate, updated digital maps that require expensive equipment and specialized expertise. The usual technique for creating and updating regional maps is aerial photogrammetry. The updating process takes place every few years, depending on economic feasibility in each country. Integrated navigation systems have been increasingly adopted, as they are less costly, more accurate, safer, more effective and use fewer ground control points (GCP) than conventional methods [20]. The use of digital cameras provides high-resolution images. This technique captures the roofs of buildings perfectly but has difficulties in capturing points of the façade that are sometimes offset from the roof line [21]. The development of oblique cameras partially corrects this problem [22], but the technique is still in its infancy [23, 24]. Other main drawbacks of aerial photogrammetry are the fact that it uses expensive equipment and is dependent on weather conditions. In 
the Middle-East, which is the area addressed in this article, optimal flying conditions are limited to the period between November to March. On the contrary, in North countries between the complementary months since the snow cover the territory in the last fall and winter.

A more economical solution is RPAS (Remote Piloted Aerial Systems). These recent aerial platforms have the same flight restrictions in border areas as traditional planes and even inside countries. In this last case, restrictions vary in each country, depending on the regulations that are in force [25-28]. Flight restrictions have led to the need for another method for frequently updating basemaps in conflictive areas.

The alternatives are high-resolution satellite images that offer several advantages for updating existing topographic maps [29-32]. For example, a single satellite scene covers a large area, from less than $65 \mathrm{~km}^{2}$ for OrbView-3 to over $270 \mathrm{~km}^{2}$ for Quickbird [33]. Hence, the survey costs may be lower using this method. However, even though the resolution of the images is high, it is not high enough to obtain large-scale cartography [34].

Therefore, terrestrial techniques must be considered. Traditional methods such as the use of total station, terrestrial photogrammetry, or Terrestrial Laser Scanning (TLS) are labour intensive, time-consuming, costly (due to field operation costs), sometimes dangerous and highly disruptive to a town's traffic. In harsh environments (areas with high temperatures or high humidity, desert areas and border areas), traditional survey methods may put the surveyor's life in real danger. In this environment, collecting data for a large area may take months because surveyors can only work at certain times when the temperature is acceptable. The only option in this case is to use terrestrial techniques such as the MMS that allow us to cover mediumsized areas at large scales [35]. This technique integrates laser scanning and photogrammetry systems with GNSS and Inertial Measurement Units (IMU), which work together to continuously calculate the vehicle position and orientation, and Distance Measurement Units (DMI). These systems are installed together on a land-based vehicle that is driven continuously to capture three-dimensional point clouds and imagery data from the required site.

These techniques (digital photogrammetry and laser scanning, independently from the platform) provide point cloud data, which are required to obtain vector features in/for the basemap. To undertake these tasks efficiently, automatic methods are needed, since data management is one of the most time-consuming processes.

In recent years, many algorithms have been developed for automatic and semi-automatic feature extraction from a $3 \mathrm{D}$ point cloud. The semi-automatic feature extraction technique requires significant user interaction to extract elements and validate the results [36]. We have focused on the use of data from MMS to extract urban elements.

The extraction of urban features and roads from mobile LiDAR point clouds is more complex, due to a lack of explicit geometric features and the huge quantity of elements [37]. The first step for many authors is separation of Ground Points (GPs) and Non-Ground Points (NGPs). Here, the author focuses on classification methods for point clouds obtained by MMS, considering information on the laser scanner's trajectory. These methods assume that the GPs lie below the trajectory of the laser scanner [38]. One study [39] uses slope analysis to filter GPs, while another study [40] uses slope and elevation information along the scan line to detect GPs. Other authors detect and remove GPs using voxel-based ground elimination by considering terrain fluctuations $[12,41]$. Then, the road surface is extracted.

Recent studies [12][14] proposed two methods with MMS as the data capture method: using the trajectory and managing the data to find linear patterns. Another study took advantage of the structure of the MMS and used other information such as signal intensity in addition to the geometry [19]. In their study Rodríguez-Cuenca et al. [15] took advantage of the rasterization of the point cloud and then from the image considered the number of pixels in weight and the intensity to determine the road curbs. Once the roads have been extracted, there are various methods for extracting the main elements. They used methods based on Principal Component Analysis (PCA) to identify pole-like objects in irregular point clouds. The extraction of pole-like objects and tree trunks from irregular point clouds was also the focus of other studies $[13,15-18,42-44]$. 
Some studies developed a percentile-based method with respect to the shape, height and size of light poles. Other authors extracted poles by analysing scan lines rather than raw point clouds. Most 3D urban furniture features can be extracted automatically with a high success rate, except for manhole covers [38].

A previous study of Commandre et al. [45] presents a method for automatic detection and localization of manhole using very high-resolution aerial images by deep convolutional neural network. Manhole cover localization is a challenging due to the variance of object colours, non-uniform background, shadows and being small objects to be detected from aerial images. In addition, manholes suffer from occlusions, differences in light exposure, rust and dirt. To minimize these problems, the propose of Timofte and Van Gool [46] is to use images taken from a moving van. Errors in terms of false detections and missed manholes must be very low for automated methods to be useful at all, but this has not been achieved for now. This is the main reason why human operators still carry out most of this work. For the first time, a previous study of Zhang [47] added a system based on vision, which was used successfully for the task of manhole mapping. He utilized automated extraction of manholes and curbs on images obtained from the point cloud.

Yu et al. [48] proposed MMS to capture a point cloud that is rasterized in a 2D intensity image, then a marked point process-based detection algorithm for the generated georeferenced images to detect road manhole and sewer well covers. The problem with this kind of transformation from point cloud to image is that part of the information can be lost.

For urban planning other important elements are buildings. Some studies proposed a methodology to extract urban building using airborne laser scanner LiDAR only [49] and others complete the information from very high resolution (VHR) imagery to address the problems with shadow and spectral confusion [50]. All of them are based on data provided from an airborne acquisition. However, these techniques are not allowed in all the areas and countries since sometime there are flight restrictions due to proximity to military zones, border between countries, etc. For these reasons, techniques to capture from the surface are the unique suitable option to cover all the urban area. However, these techniques have the drawback of occlusions, for that some studies $[51,52]$ use high-resolution satellite imagery to extract building outline boundaries.

\section{PROPOSED METHODOLOGY}

The proposed methodology includes automatic manhole detection from 3D point clouds measured by the MMS sensor and completion of the façades of buildings that are hidden in the survey with MMS. In this last process, other input is the orthoimages obtained from the Quickbird satellite. The next sections describe the phases of the proposed methodology for each kind of element.

\subsection{Manhole Detection}

Manhole height is almost equal to ground height, which causes difficulties in edge detection. The parts of the manholes that can be seen are affected by the daily passing of cars, which may result in an apparent change in their shape. These difficulties make the automatic detection process challenging. In this study, a manholes detection method, based on their shape (usually rectangular or circular) and the intensity information from the returned laser beam pulse, was developed.

Figure 1 shows the flowchart of the procedure in every step of the method. First, a check is done to confirm that the LiDAR format is correct, otherwise a suitable format should be uploaded. The manhole detection algorithm starts by defining the variables that will be used, such as the coordinates (X, Y and Z), the time (t) and the intensity (i). Then the LiDAR data in LAS format is uploaded.

The intensity variable is used to segment the point cloud regarding manhole material and the time variable is used to link other variables, as the LiDAR data is recorded by time. Finally, the coordinates are used to detect the shape of the manhole. 


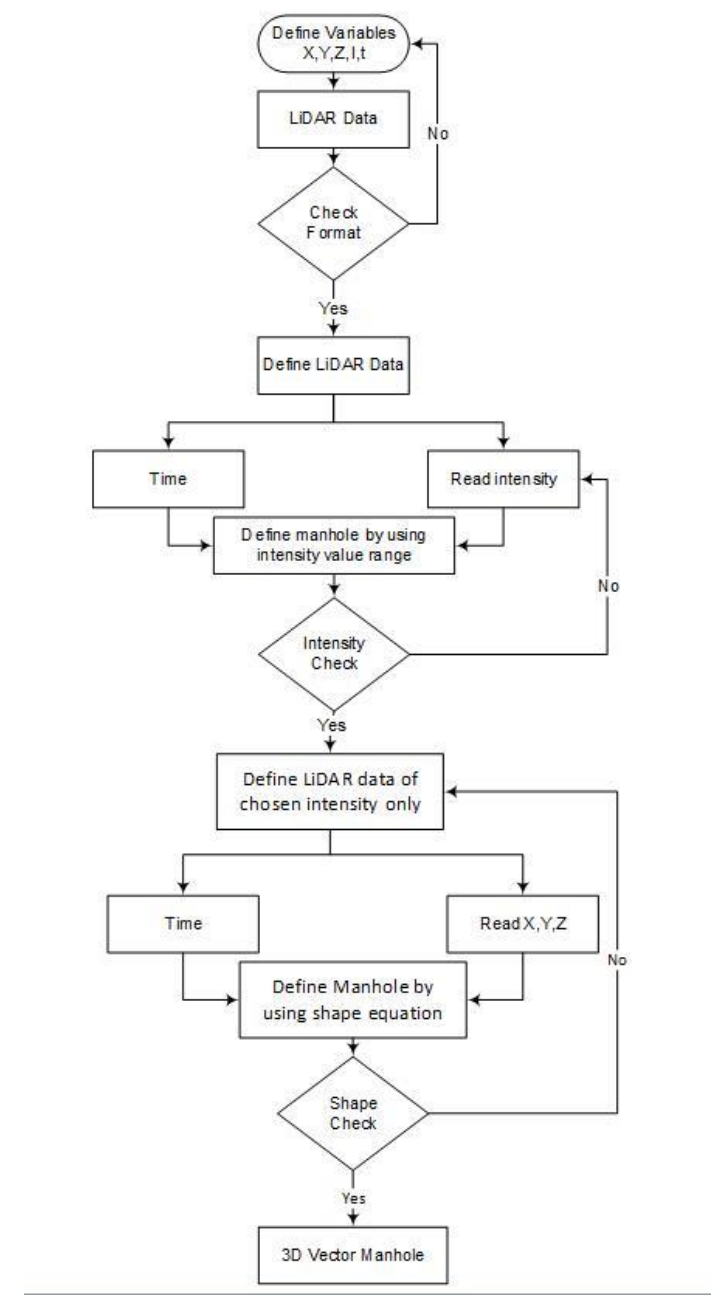

Figure 1. Manhole detection workflow

\section{Intensity Threshold}

Each road feature has a different intensity value based on its material characteristics. The manholes have a different value of intensity than the points in the cloud around them that belong to the pavement and other elements. These values are determined based on the manhole material and the wavelength of the laser beam used. Figure 2. A) shows the point cloud by intensity values. Metallic objects such as manholes or gates are shown in red, while the pavement and the walls have different intensity values. This characteristic is very useful to segment the point cloud. 

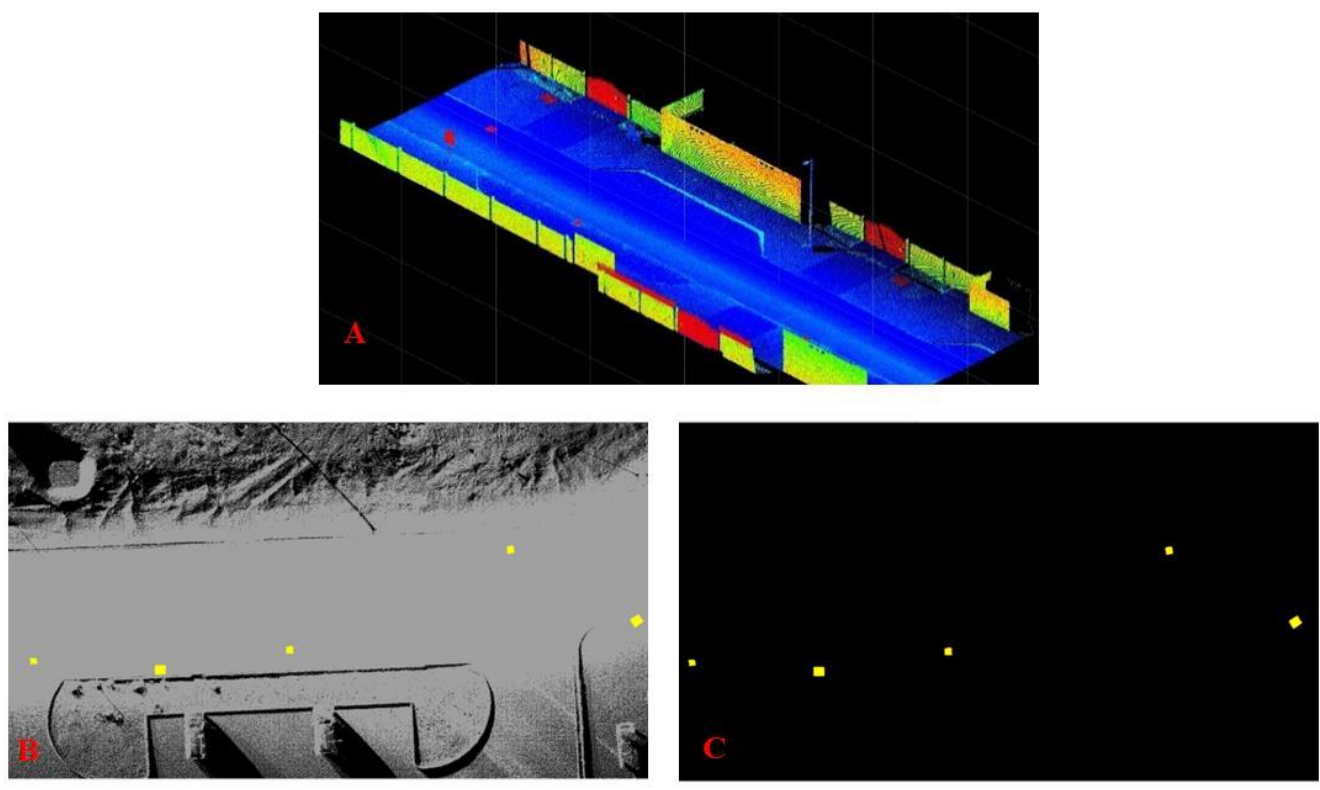

Figure 2. A) Intensity image where the metallic element is shown in red; B) Intensity image in grey scales, in it the manholes have been highlighted in yellow; C) Manholes after the extraction using shape.

First, the proposed algorithm defines the intensity for the elements to be detected. If the object intensity is different from the required value, it will skip this feature and search for the next one. The intensity value should be between the minimum and maximum intensity values. Objects with the required intensity will be put through the next check, which is the shape check.

$$
I_{\min }>I_{\text {point }}>I_{\max }
$$

Points that satisfy the condition whose intensity is in the interval for the manhole material are saved in a new file. Figure 2. B) and C) show the patches that remain after the first intensity filter.

The next step is to check the shape. Since we are looking for manholes, the task is easier than searching for other irregular shapes. In all cities, manholes are square, rectangular or circular and their dimensions are known, as they follow a standard. Another property we can use is that the points that define the surface of manholes are in a profile sequence and groups. This helps us in this step.

The algorithm will check the shape of the matched intensity objects and skip objects that are not the required shape, see Figure 3. The parameter given by the operator is the sides for rectangular manholes or the radius for circular ones. For example, for a rectangular manhole, the points that belongs to a patch must satisfy the expression of the shape $S$, Equation (1). Thus, the filtered points are divided into clusters and then into individual features/objects.

$$
\mathrm{S}=\frac{|a x+b y+c z+d|}{\sqrt{a^{2}+b^{2}+c^{2}}}
$$

where $a$ is the dimension in the $\mathrm{x}$ direction, $b$ is the dimension in the y direction, $c$ is the dimension in the $\mathrm{z}$ direction and $d$ is the distance from the origin to the required plane. Since all detected manholes are at pavement level, the coefficient $d$ will be the same as the pavement height.

The manhole features that match this known shape and dimensions will then be detected and extracted in the output. These identified cluster objects are irregular, so a last step is required to refine the shape of each identified manhole to a perfect plane with four straight sides and four right angles with equal or unequal 
adjacent sides, as per the manhole shape. To identify this perfect plane, the Minimum Bounding Rectangle (MBR) or Bounding Box (BB) is computed to obtain the envelope of each cluster object.
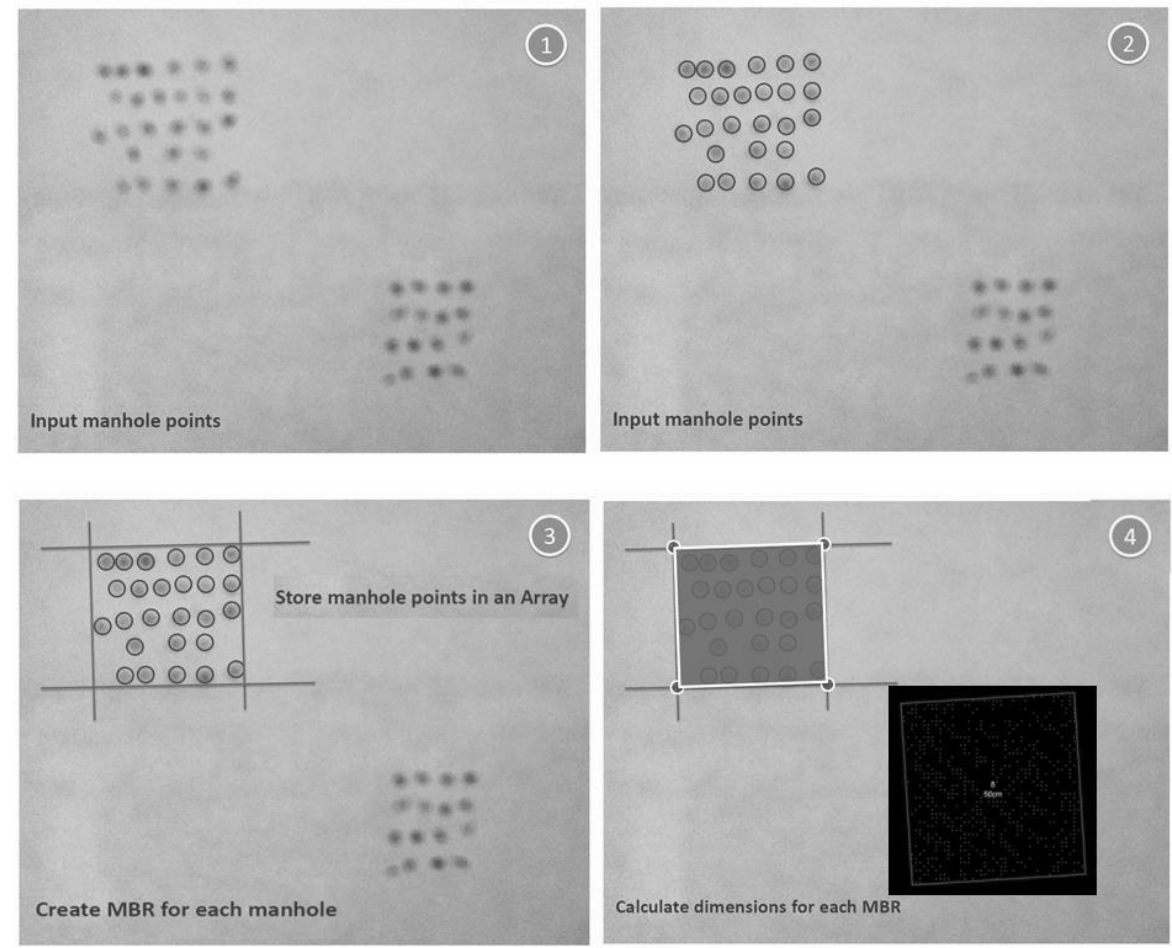

Figure 3. Manhole detection steps: 1) result of the filter by intensity, 2) Identification of the points in each cluster, 3) Obtaining the MBR of each cluster, 4) Final shape adjustment based on the known dimensions.

The process is repeated with all the known dimensions until all valid manholes with the required criteria (shape and intensity) are detected.

The proposed methodology is suitable for whatever city in the world, since the values of the intensity and size are configurable and can adjust based on other local manhole geometry and material to fit any geographical location or standards.

\subsection{Buildings}

LiDAR sensors in the mobile mapping system do not cover all building corners, so it is difficult to capture a complete building layout from MMS to obtain the footprint of the building and update the basemap. To complete the missing information, we need to find a solution using satellite imagery, the available LiDAR data and the images from the MMS cameras.

The satellite image was captured from the QuickBird satellite with $0.61 \mathrm{~m}$ resolution. One problem of the available orthophoto is that it is not a true orthophoto, so the elements have more displacement on the top. Therefore, the footprint and the roof do not coincide in the image. The accuracy of the point cloud collected by the MMS system is greater than that of the satellite image coordinates. Consequently, the coordinates from the MMS will be set as the ground control.

Therefore, first we use satellite imagery to automatically digitize the layout of all buildings in the study area with automated software tools. This provides the footprints of the buildings. Then, the visible corners of buildings from the LiDAR point cloud are imported and a fitting process is performed by comparing them with those corners of the building from the satellite image.

Two processes (Figure 4) are carried out in this phase to establish the most suitable for the adjustment in these conditions. 


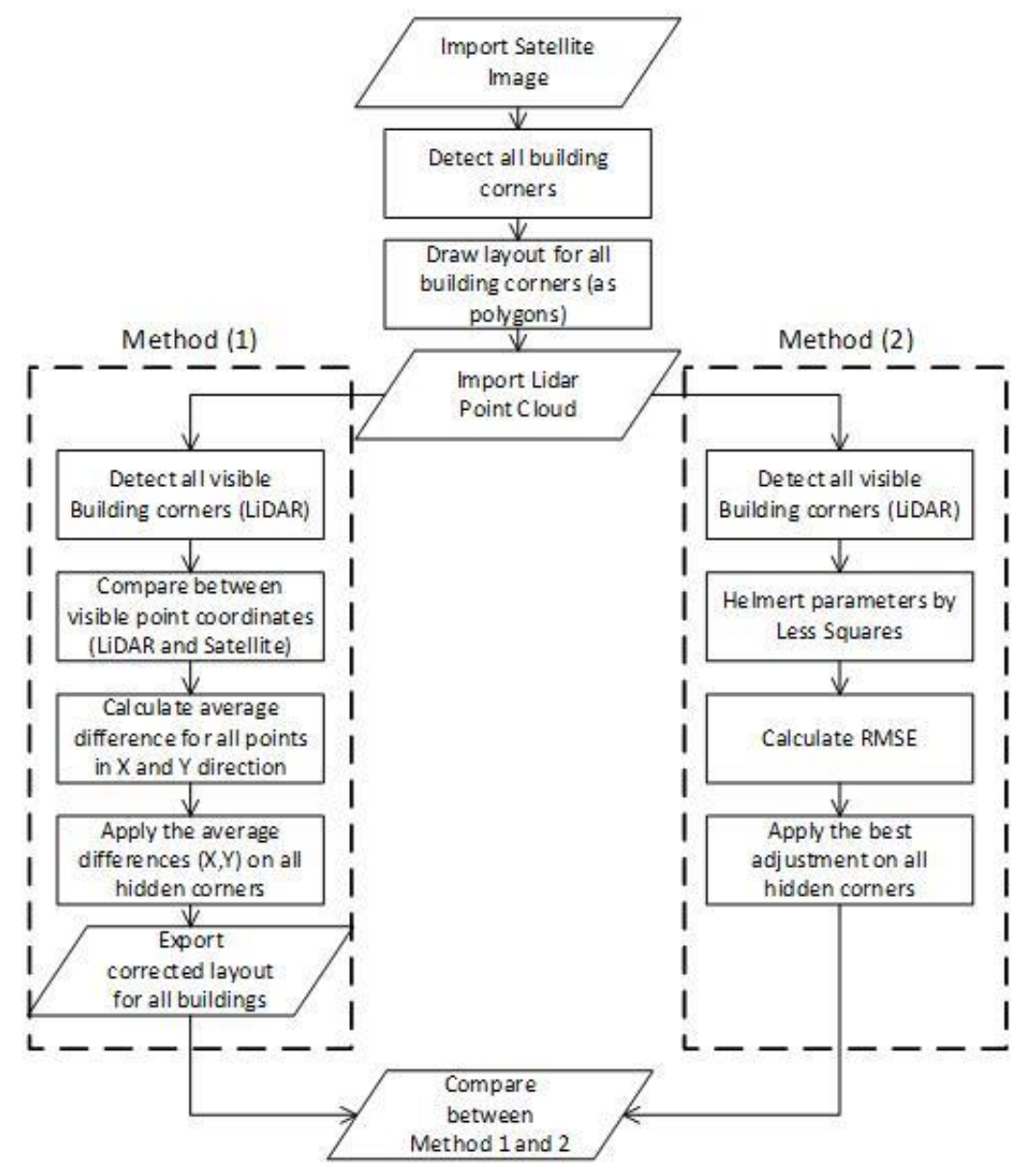

Figure 4. Hidden building corners detection workflow (Method 1 on the left and Method 2 on the right)

In Method 1: average_shift, the differences in X and Y directions are measured in the corners, where LiDAR and satellite data are available. Then, the average value for all corner differences in the $\mathrm{X}$ direction is applied to all buildings in each area extracted from LiDAR data, and the same process is applied in the Y direction. Equations (2) and (3) are shown below in the $X$ and $Y$ direction. The missing corners are obtained by applying these shifts (fitting differences), which are computed for each building.

$$
\begin{aligned}
& \text { Fitting Difference } X=\mid \text { Difference } X \mid- \text { Average Difference } X \\
& \text { Fitting Difference } Y=\mid \text { Difference } Y \mid- \text { Average Difference } Y
\end{aligned}
$$

The resulting layout, with corrected LiDAR data for the building layout, are used to extract the missing corners from the LiDAR sensor to complete the building features.

The second method is a Helmert 2D transformation. Since the characteristics of the zones and buildings are different, first we compute the transformation parameters, namely the translation in $X$ and $Y$, the scale factor and one rotation for different areas, and then these parameters will be used to compute the new coordinates, $\mathrm{X}_{\mathrm{L}}$ and $\mathrm{Y}_{\mathrm{L}}$, in Equations (4) and (5).

$$
\begin{gathered}
X_{L}=T_{X}+a_{1} X_{S}-a_{2} Y_{S} \\
Y_{L}=T_{Y}+a_{2} Y_{S}+a_{1} X_{S}
\end{gathered}
$$

Where $a_{1}=\lambda \cos \alpha, a_{2}=\lambda \sin \alpha$, and $\lambda$ is the scale factor and $\alpha$ the rotation between both coordinated systems. 


\subsection{Other elements}

In this study, the road features, building details and building corners were extracted using commercial software (TopoDOT C3D tool).

This tool is part of CAD software and detects features by their geometry and intensity. Each feature (light poles, footpath, driveway and street signs, etc.) was defined as a cell, saved to a library, and snapped into the model. The cell enables the software to recognize each feature with its attributers and is saved in CAD format.

For features that cannot be defined as cells, various tools can be used depending on the required features. For example, a tool can be used to detect street centrelines by their intensity values and has been drawn based on their intensity values. There are three main ways to detect features automatically using TopoDOT C3D: define by cell, intensity range and define approximately by the height of the feature (so that the tools can easily define the feature). The defined cell is saved to be used to detect features later. Then this cell is dropped into the point cloud to obtain the $\mathrm{x}, \mathrm{y}$ and $\mathrm{z}$ values. The intensity values range option to detect the features' intensity can be used for this purpose. Then, these features can be searched in the selected intensity range. In this study, we used cells whose characteristics are known.

Extracted road features include the road centreline, road edge (curb), streetlights, street signs and top edges of buildings. A sample of different features in the study area is shown below in Figure 5 (the features include a street sign, curbs and a light pole).
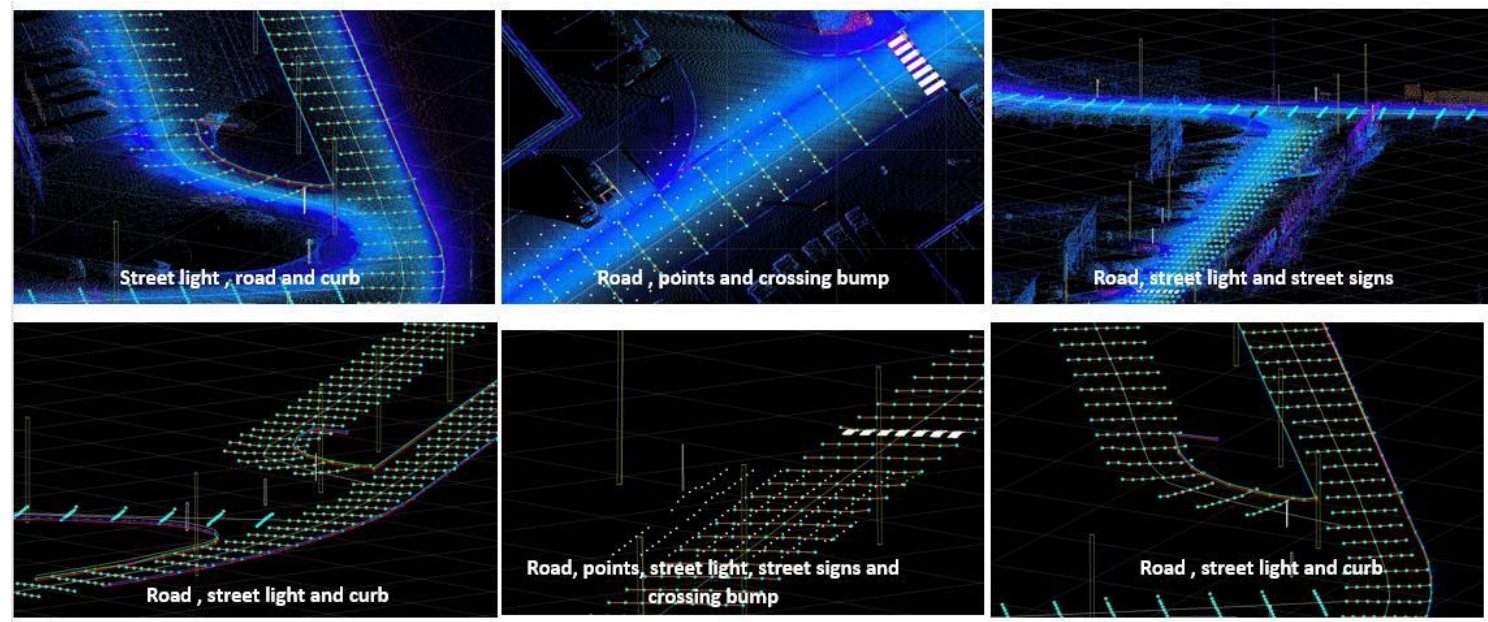

Figure 5. Sample of features in the point cloud for the study area

Although the available software is very powerful for the feature extraction processes, it has some limitations, which require manual work or extra work. These limitations can be summarized as follows:

1. Due to the size of Lidar data files, they must be divided so that they can be opened easily.

2. Automated feature detection cannot detect features with highly accurate positioning. Therefore, manual detection is required to enhance feature positioning and height accuracy for features such as streetlights, street signs and trees.

3. Some features, such as buildings and manholes, required manual extraction.

4. For some features, a cell must be built to define the feature in the software. Then, this cell must be dropped on data to obtain $\mathrm{x}, \mathrm{y}$ and $\mathrm{z}$ values from the point cloud. Sometimes, cells may not be dropped correctly. In this case, the entire process will be repeated. 


\section{CASE STUDY: ABU DHABI}

The methodology was used to update the basemap of Al Ain, a city in the Emirate of Abu Dhabi (United Arab Emirates, UAE) on its border with Oman, at a scale of 1/1000. For large and medium scales, basemaps are regularly constructed and updated using aerial photogrammetry [11] or Airborne Laser Scanner (ALS). However, in our case study located near the border, the direct use of aerial photogrammetry is restricted, as it occurs in several areas worldwide.

The basemap is the government's main resource for determining ground reality and private property boundaries and it can be used to draw up cites' master plans. The basemap accuracy specification is very conservative, at 15 centimetres absolute accuracy. Traditional topographic surveys should be minimized. As they are limited in harsh weather conditions, new survey methods must be adopted.

In any other case, the mail survey would be undertaken by aerial photogrammetry and then some parts completed or updated by a traditional topography survey or MMS LiDAR. Due to the specific characteristics of this area, which is near the Oman border, MMS is applied as an accurate, cost-effective method of obtaining the basemap. For this reason, we explain briefly the entire process from data capture to automatic element extraction by point cloud segmentation.

The MMS methodology follows a specific workflow, as shown in Figure 6. The initial step is to plan, encompass and determine the strips to be covered during the survey process. The second step is data acquisition, and this entails controlling the survey and reviewing the route plan, as well as system status information. The third step is data processing, which includes processing the positioning and the GNSS data to determine the trajectory utilized to georeference the point cloud data. The fourth step is generating and converting the point cloud data into vector features by means of the classification and extraction process. The final step is the quality control process to enhance and evaluate the results and draw up the final basemap.

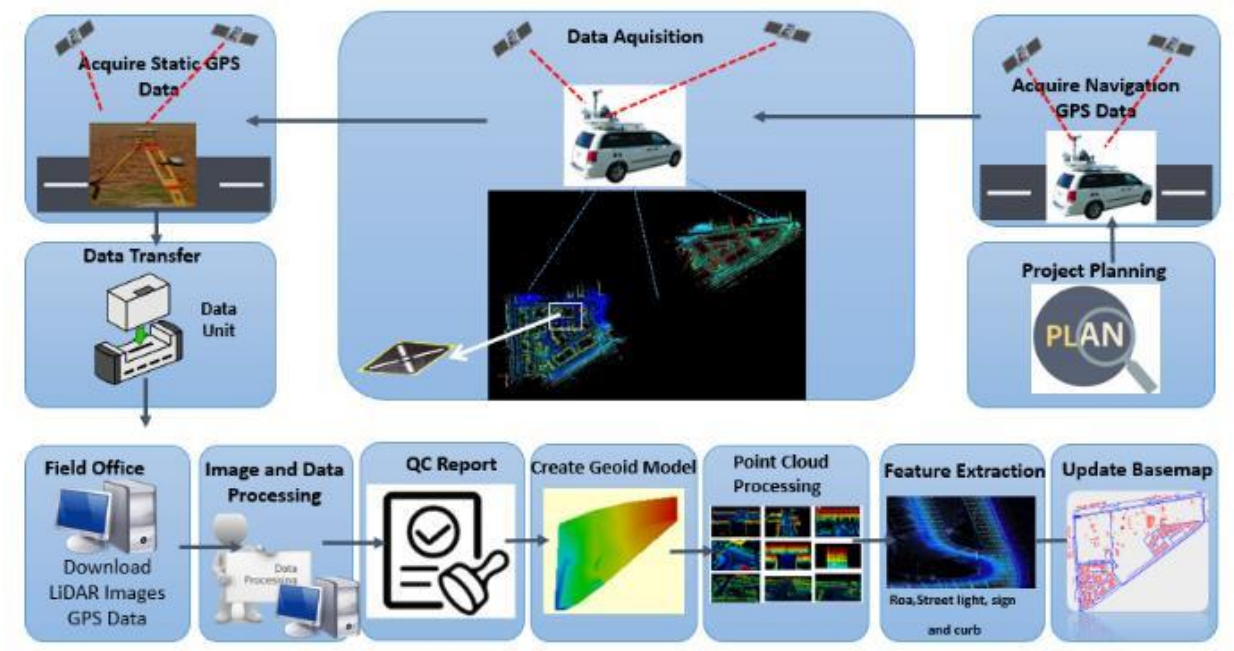

Figure 6. Proposed workflow to update basemap

The selected zone covers $1.5 \mathrm{~km}$ by $1 \mathrm{~km}$ and includes three areas with different urban patterns. The first zone (Area 1) has low buildings and a high level of urbanization, the second zone (Area 2) has high rise buildings (around 10 floors) and a low level of urbanization and the third zone (Area 3 ) is peri-urban (Figure 7). It is important to probe the system and the algorithm to extract elements in different urban patterns, since their characteristics can be a drawback. Urban patterns may affect the accuracy of the capture (for example, high buildings make good signal reception difficult) and the characteristics, as a shadow can make up the intensity and colour of the objects and some elements can hide others. 


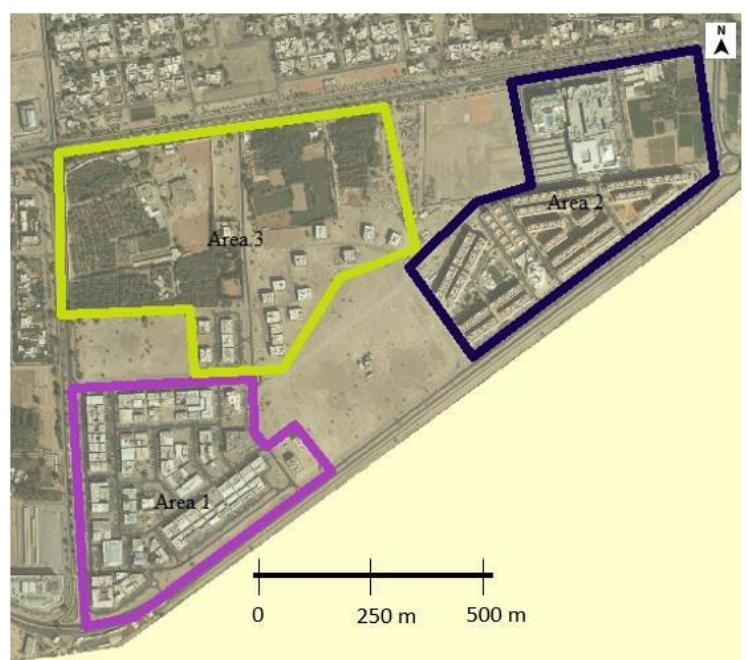

Figure 7. Zones with different urban patterns in the study area

\subsection{Data Acquisition}

The data acquisition process was carried out with the Optech Lynx Mobile Mapper system, composed of LiDAR, which allows us to measure 500,000 points per second with a $360^{\circ} \mathrm{FOV}$ (Field of View) to provide absolute accuracies (root mean square error, RMS) of $0.02 \mathrm{~m}$ in the $\mathrm{X}$ and $\mathrm{Y}$ positions, and $0.05 \mathrm{~m}$ in the $\mathrm{Z}$ position [36, 53-54]. Differential GPS post-processing is used to determine ground control stations either using base stations or Abu Dhabi GNSS Reference Network Stations.

The MMS sensors and hardware has been conditioned to operate at the high temperatures in UAE, which reach 50 degrees centigrade in summer, while MMS should be used at temperatures that do not exceed 40 degrees to maintain suitable optical and electronic performance.

The post-processed position and orientation accuracies of both trajectories collected in two different days were analysed. The maximum error in the northing axis was found to be from $0.064 \mathrm{~m}$ to $0.048 \mathrm{~m}$, the maximum error in the easting axis was from $0.085 \mathrm{~m}$ to $0.062 \mathrm{~m}$, and the maximum error in altimetry was from $0.130 \mathrm{~m}$ to $0.072 \mathrm{~m}$.

To transform the ellipsoidal elevation of the MMS into orthometric elevations, a geometrical geoid model based on 31 GCP coordinates the UTM zone $40 \mathrm{~N}$ (WGS84).

The area was scanned with a density of $2-3 \mathrm{~cm}$. The final point cloud had a total of 1300 million points. To evaluate point cloud accuracy, 12 GCPs were used in the point cloud that was created and the results were compared with measurements from the current basemap at a scale of 1/1000. Figure 8 presents the distribution of the GCPs used to compare both the trajectory and the point cloud. 


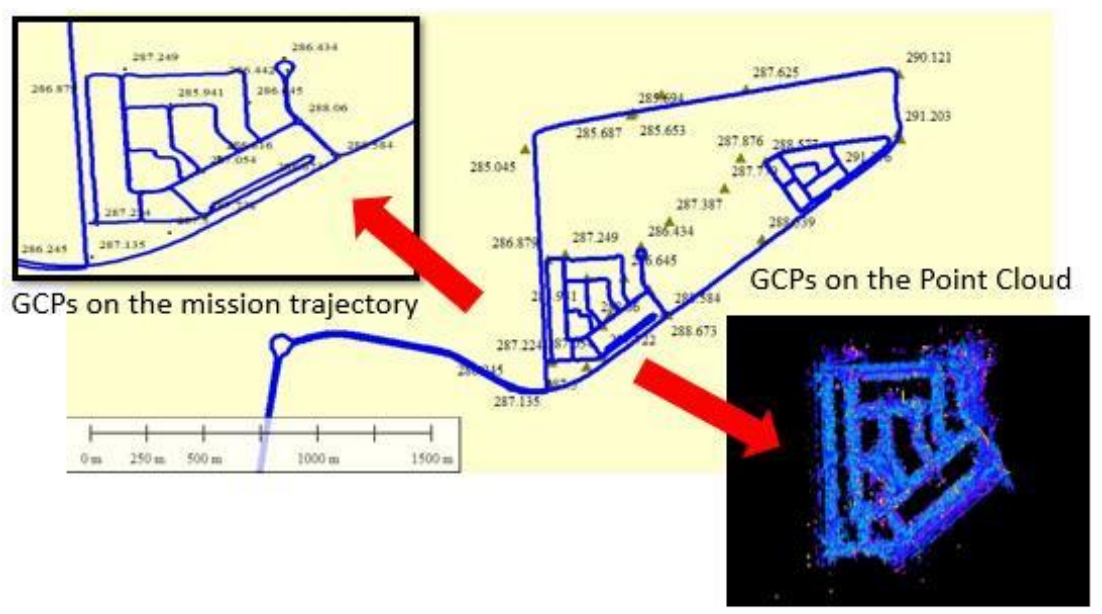

Figure 8. Ground Control point distribution in the study area

The average difference for these points was $0.017 \mathrm{~m}$ in planimetry and $0.009 \mathrm{~m}$ in $\mathrm{Z}$ coordinates respectively. The RMSE for these point differences were $0.022 \mathrm{~m}$ in planimetry and $0.020 \mathrm{~m}$ in altimetry, as shown in Table 1. These differences are not significant if the scale of the basemap is considered.

\begin{tabular}{llll}
\hline & Difference $\mathbf{( Z )}$ & $\begin{array}{l}\text { Difference } \\
(\mathbf{X})\end{array}$ & Difference (Y) \\
\hline Mean (m) & 0.009 & 0.002 & 0.017 \\
\hline RMSE (m) & 0.020 & 0.005 & 0.020 \\
\hline Min (m) & -0.017 & 0.000 & 0.002 \\
\hline Max (m) & 0.042 & 0.018 & 0.043 \\
\hline
\end{tabular}

Table 1. Difference between known GCP coordinates and measured coordinates from the point cloud

\subsection{Feature Extraction}

In this section, the results of the extraction are shown for roads and a lot of urban furniture features, including manhole covers. Some items must be extracted manually due to their complexity, including driveways, car parks or footpaths. The automatic detection was performed by a cell whose design was based on two parameters: height and intensity values. The values of the height and intensity parameters set for each feature detection are shown in Table 2.

\begin{tabular}{llc}
\hline Features & \multicolumn{2}{c}{ Parameters } \\
\hline & Height & Intensity \\
\hline Road edges (curb) & $0.18 \mathrm{~m}$ & \\
\hline Road centreline & & $20-55$ \\
\hline Building & $6-24 \mathrm{~m}$ & \\
\hline Light poles & $10 \mathrm{~m}$ & \\
\hline Street signs & $1.5 \mathrm{~m}$ & \\
\hline Trees & $3-5 \mathrm{~m}$ & \\
\hline Manhole & & $2-42$ \\
\hline
\end{tabular}

Table 2. Detection type and parameters for each feature

This method can detect up to $96 \%$ of each feature. In the study, another run was performed to detect the remaining $4 \%$ manually. The feature quantity and successful detection rates are shown in Table 3.

The success rate was better in Area 1 than in Areas 2 and 3, because in Area 1 there is a proper roadway for LiDAR vehicle movement that is better than in Areas 2 and 3. In Area 3, cars cannot be driven on most 
of the streets. The roadway allows a clear, full view of the surveyed area and resulted in successful feature detection and extraction at a higher percentage than in Areas 2 and 3 (Table 3).

\begin{tabular}{lllllll}
\hline & Area 1 & Area 2 & Area 3 & \\
\hline Features & $\begin{array}{l}\text { Success } \\
\text { rate (\%) }\end{array}$ & Quantity & $\begin{array}{l}\text { Succes } \\
\text { s rate } \\
(\%)\end{array}$ & Quantity & $\begin{array}{l}\text { Success } \\
\text { rate }(\%)\end{array}$ & Quantity \\
\hline $\begin{array}{l}\text { Road edges } \\
\text { curb stones) }\end{array}$ & 95 & $9.6 \mathrm{~km}$ & 70 & $12.8 \mathrm{~km}$ & 60 & $3.8 \mathrm{~km}$ \\
\hline $\begin{array}{l}\text { Road } \\
\text { centreline }\end{array}$ & 98 & $5.2 \mathrm{~km}$ & 80 & $7.2 \mathrm{~km}$ & 90 & $3.2 \mathrm{~km}$ \\
\hline Buildings & 85 & 62 & 65 & 19 & 45 & 9 \\
\hline Light poles & 100 & 122 & 100 & 134 & 40 & 21 \\
\hline Street signs & 100 & 119 & 100 & 225 & 40 & 33 \\
\hline Trees & 75 & 25 & 75 & 66 & 90 & 128 \\
\hline
\end{tabular}

Table 3. Quantity and successful detection rate for the feature detection process for each area

The successful rate for buildings is lower in all three areas, due to façades hidden by the buildings themselves, trees or other elements. Therefore, we extracted additional building façade information from satellite images. The results are explained below in section 4.4.

For the use of collected LiDAR data, the first and second returned pulses for the manholes were the strongest returns. These two returns were useful to detect accurate shapes using a script in MATLAB software. Based on field measurements, three square shapes of manholes were found in the study area with dimensions of 80, 65 and 55 for the $a$ and $b$ values of Equation (1).

For the extraction of manholes, we will use the algorithm described above. The first and second returns of the pulses that were received, analysed in the time parameter, will correspond mainly to manholes, since the signal returned by metal is more intense. The next parameter to be established is the intensity, in our case that of steel manholes. For the wavelength of the laser used and the angles of incidence of the laser beam on the pavement, the values of intensity correspond to between 2 and 42 . The algorithm used is the same for the three sizes of manholes, since the different dimensions only has to be entered once in each iteration.

To adjust the plane of Equation (1), the square edge corresponds to $a$ and $b$ parameters of the plane, while $c$ will be zero. Then, the value of parameter $d$ will correspond with the height of the pavement over the road. In the case of Abu Dhabi, it is $18 \mathrm{~cm}$.

Table 4 shows the completeness and correctness for each area with a different urban pattern. The values are computed from Equations (6) and (7) respectively. The successful detection percentages for each shape were $97 \%, 97.5 \%$ and $87 \%$ for areas 1,2 and 3 respectively, while the percentages of the detected manhole correctness were $98 \%, 98 \%$ and $93 \%$ for areas 1, 2, and 3 respectively. The worst rates were obtained for the same features in peri-urban areas (Area 3), due to the high vegetation. The reference value for the total number of manholes was calculated from the current accurate basemap (1730 manholes). Out of these, a total of 1678 manholes were detected, which represents a 97\% success rate.

$$
\begin{aligned}
& \text { completeness }=\frac{\text { manhole automated detection }}{(\text { manhole ground truth }) \cdot 100} \\
& \text { correctness }=\frac{\text { manhole automated detection }}{(\text { manhole }+ \text { non }- \text { manhole automated detection }) \cdot 100}
\end{aligned}
$$

The manhole extraction process was applied to Areas 1,2 and 3 of the study area. A total of 1414 manholes were extracted from area 1, while 237 manholes were extracted from area 2, and 27 manholes from area 3 , as shown in Table 4. 


\begin{tabular}{|c|c|c|c|c|c|c|c|}
\hline \multirow[t]{2}{*}{ Area } & \multirow[t]{2}{*}{$\begin{array}{l}\text { No. of } \\
\text { Actual } \\
\text { Manholes }\end{array}$} & \multirow[t]{2}{*}{$\begin{array}{l}\text { No. of } \\
\text { Detected } \\
\text { Manholes }\end{array}$} & \multirow{2}{*}{$\begin{array}{l}\text { No. of } \\
\text { Un- } \\
\text { Detected } \\
\text { Manholes }\end{array}$} & \multirow{2}{*}{$\begin{array}{l}\text { No. of } \\
\text { False } \\
\text { Detected } \\
\text { Manholes }\end{array}$} & \multirow{2}{*}{$\begin{array}{l}\text { No. of } \\
\text { Correct } \\
\text { Detected } \\
\text { Manholes }\end{array}$} & \multicolumn{2}{|c|}{$\begin{array}{l}\text { Accuracy } \\
\text { Evaluation }\end{array}$} \\
\hline & & & & & & $\begin{array}{l}\text { Completeness } \\
\text { (\%) }\end{array}$ & $\begin{array}{l}\text { Correctness } \\
(\%)\end{array}$ \\
\hline Area 1 & 1456 & 1438 & 42 & 24 & 1414 & 97.11 & 98.33 \\
\hline Area 2 & 243 & 242 & 6 & 5 & 237 & 97.53 & 97.93 \\
\hline Area 3 & 31 & 29 & 4 & 2 & 27 & 87.09 & 93.10 \\
\hline Total & 1730 & 1709 & 52 & 31 & 1678 & 96.99 & 98.18 \\
\hline
\end{tabular}

Table 4. Completeness and correctness of manhole extraction for the three types in areas 1, 2 and 3

Although the script showed a high successful detection rate, some manholes may have been overlooked due to a change in intensity values or the fact that they are covered by sand as they are close to ground level. Detection of manholes fails when there is any obstacle, such as dust and cars, hiding the manhole and therefore it cannot be captured by the LiDAR completely (see Figure 9). In this case, the algorithm cannot be adjusted to the shape and the automatic detection fails.

Area 3 was the most difficult due to its characteristics, although we could survey part of it. A total of 27 manholes were detected in this area with a completeness percentage of $87 \%$ and a correctness percentage of $93 \%$. The completeness percentage was the lowest in this area, because it has a lot of objects and sand covered manholes. This makes the detection survey process very difficult as it depends on the intensity, shape and returns of manholes. Manholes could be detected from a field survey or images from aerial photogrammetry, if these kinds of flights were not forbidden in the area, as mentioned previously.

The limitations of commercial software to extract manholes led us to apply this methodology that improved as performance of manhole extraction as computational cost, table 8 .

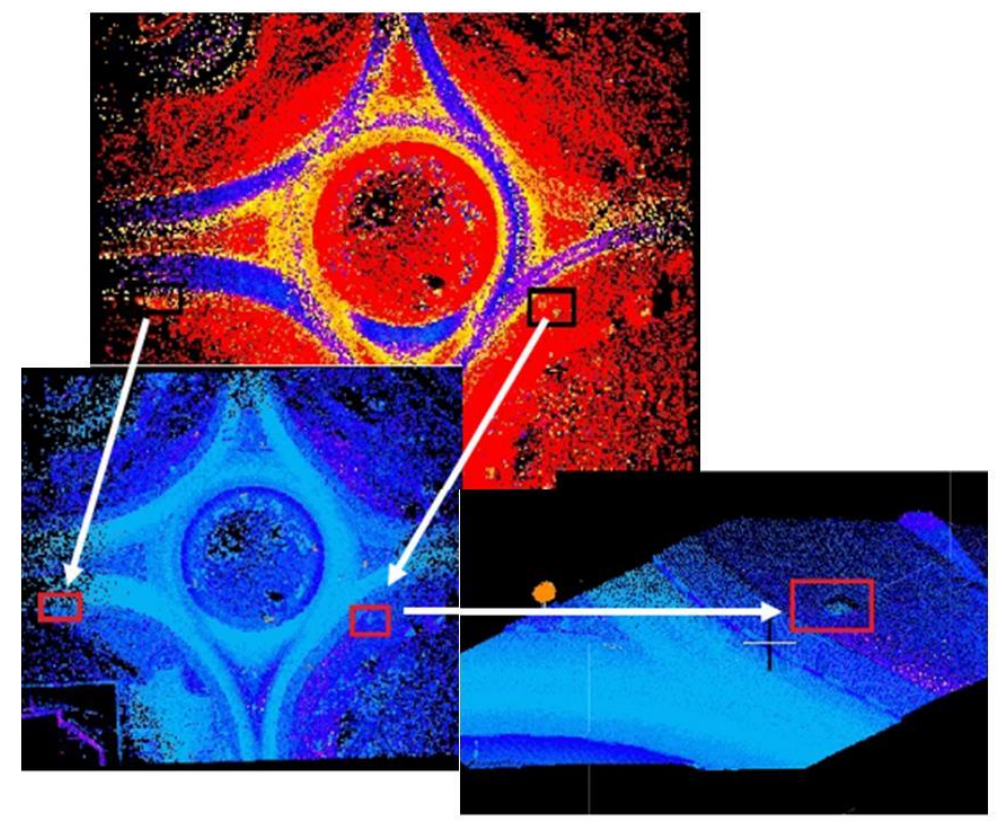

Figure 9. Sample of undetected manholes in the survey area

Most of the current available methods are using image processing by creating intensity-based images (rasterized process) from LiDAR point cloud data to extract manhole [55] or directly from aerial images [45]. While we applied this methodology directly from the LiDAR point cloud, based on the beam intensity value that define the manhole and their geometry previously known for the city. Avoid the rasterization allows an improvement of the results regards the completeness and correctness percentages, we have detected around $98 \%$ versus $51 \%$ in [45]. It has been noticed that our study areas have many occlusions not only because the cars and objects but also by the sand that cover the streets in Abu Dhabi. Moreover, we 
use of the geometrical shape of the manhole that helps in reducing false detection as [45] proposed to improved their method.

\subsection{Data position accuracy}

In previous sections, we discussed accuracy in terms of the completeness and correctness of the detection. Now, we focus on the position accuracy of the extracted features using as a reference (ground truth) their coordinates in the Abu Dhabi official basemap. Table 5 shows the planimetric and altimetric difference, and the statistics for minimum, maximum, average and RMSE.

\begin{tabular}{clcccccc}
\hline \multicolumn{2}{c}{ Survey Features } & $\begin{array}{c}\text { Road } \\
\text { Centreline }\end{array}$ & $\begin{array}{c}\text { Curb } \\
\text { stone }\end{array}$ & Buildings & $\begin{array}{c}\text { Light } \\
\text { poles }\end{array}$ & $\begin{array}{c}\text { Street } \\
\text { Sign }\end{array}$ & Manhole \\
\hline & Quantity & $18.5 \mathrm{~km}$ & $37 \mathrm{~km}$ & 102 & 277 & 377 & 1678 \\
\hline $\begin{array}{c}\text { Planimetric } \\
(\mathbf{X Y})\end{array}$ & Average & 0.024 & 0.010 & 0.120 & 0.012 & 0.016 & 0.009 \\
\cline { 2 - 8 } $\begin{array}{c}\text { difference } \\
\text { in meters }\end{array}$ & Max & 0.210 & 0.180 & 0.800 & 0.080 & 0.070 & 0.050 \\
\cline { 2 - 8 } & Min & 0.008 & 0.008 & 0.06 & 0.007 & 0.004 & 0.004 \\
\hline \multirow{2}{*}{$\begin{array}{c}\text { Altimetric } \\
\text { difference } \\
(\mathbf{Z}) \text { in } \\
\text { meters }\end{array}$} & RMSE & 0.038 & 0.038 & 0.015 & 0.016 & 0.030 & 0.028 \\
\cline { 2 - 8 } & Max & 0.009 & 0.014 & 0.0085 & 0.008 & 0.023 & 0.010 \\
\cline { 2 - 8 } & RMSE & 0.150 & 0.230 & 0.180 & 0.011 & 0.100 & 0.060 \\
\hline
\end{tabular}

Table 5. Comparison of accuracy between the extracted features from the LiDAR survey and coordinates in Abu Dhabi basemap

The coordinate differences obtained for all features (see the average in Table 5) are well below the threshold of $15 \mathrm{~cm}$ in planimetry and altimetry, established according to the scale of the basemap and its technical specifications. The maximum differences were found for the road centreline, curbs and buildings, and stood at around $20 \mathrm{~cm}$ for planimetric and altimetric differences. We can find a maximum of $90 \mathrm{~cm}$ for the buildings, although this was an isolated case located in area 2, where the buildings are higher and the GNSS signal has worse reception to define the position. The RMSE for all the elements is less than $4 \mathrm{~cm}$ in planimetry and altimetry.

\subsection{Building layout and filling gaps using satellite images}

In the car's trajectory, all the visible features were captured but not all of them were complete. The clearest example are the buildings. In this case, the internal walls were missing (Figure 10). Therefore, additional information had to be sought to fill the gaps. In other countries, the best solution could be a photogrammetric survey with an RPAS platform. However, due to the problem of flight permission, the only possibility in the study area was to use satellite images.

The images available for the area are orthoimages from Quickbird with a resolution of $0.61 \mathrm{~m}$. On these images, we digitalized the footprint of each building and then fitted the footprint to the corner points obtained from the point cloud. 


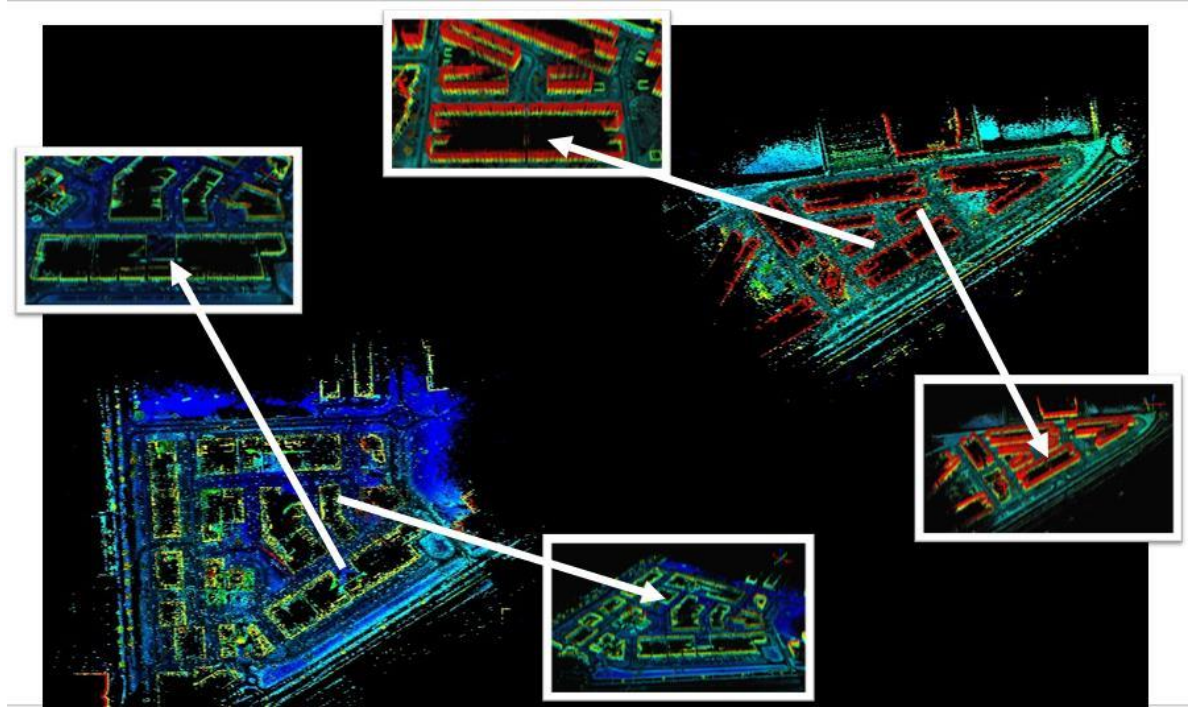

Figure 10. Point cloud details for Area 1 and Area 2 of the case study

As mentioned above, the digitization process is more accurate when the building area is small, and the building height is low. Therefore, buildings were managed in several sets according to their height.

The first step was to digitalize the 4 coordinates of each building in the satellite image (red points in Figure 11), then we used the two methods shown in Figure 2: a Helmert 2D transformation or the average shift, to fit these footprints to the LiDAR visible corner coordinates (green points in Figure 11). Then, the four corners were adjusted (blue points in Figure 11).

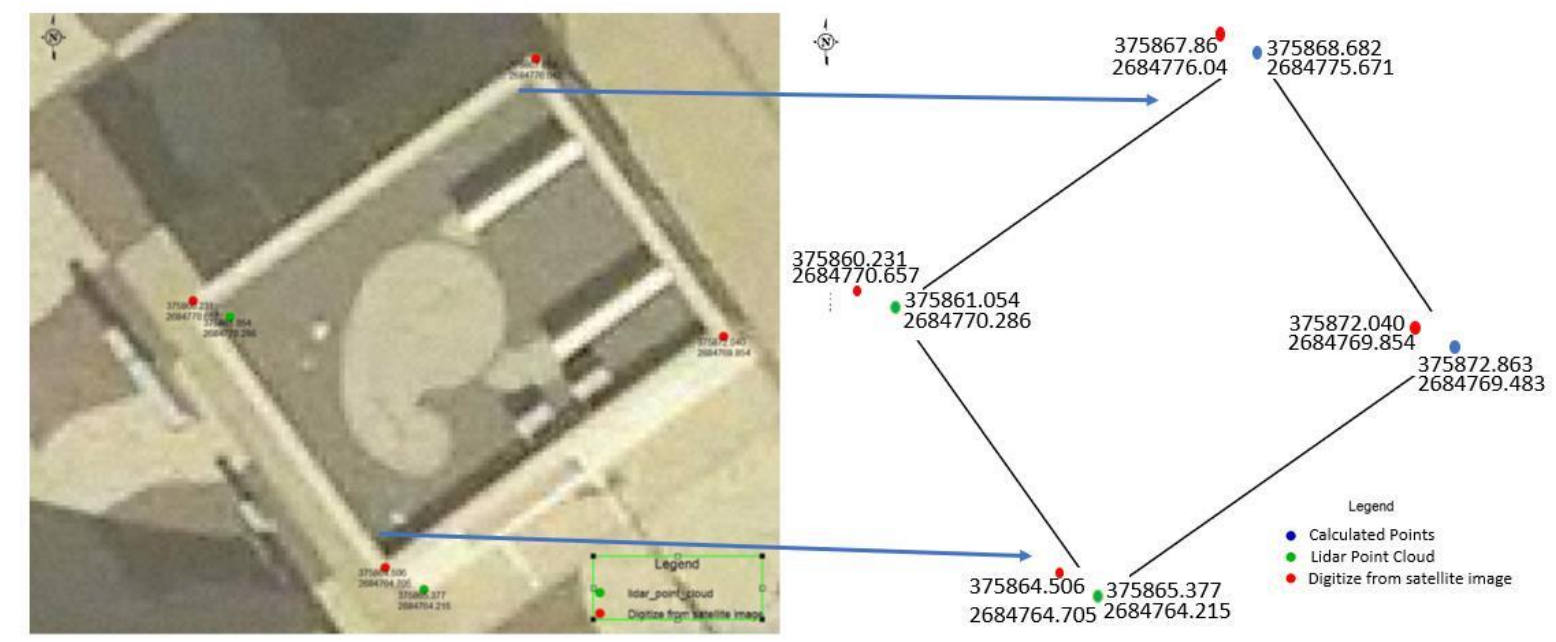

Figure 11: Example of building corners fit using satellite images

A simple approach was used to calculate the difference between the two visible points in coordinates $X$ and $Y$. The difference was calculated for each point between the measurements in LiDAR and the satellite image. The average for all these differences was calculated for $X$ and $Y$ coordinates and subtracted from the absolute difference (between LiDAR and the satellite image) for each point, to draw the new enhanced layout (fitting layout).

To compare this method with method 2 (Helmert transformation), the final accuracy for laying buildings from LiDAR data over the satellite image after the enhanced fitting process was calculated for all low-rise buildings (102 buildings) and all high-rise buildings (29 buildings) separately, Table 6. 


\begin{tabular}{lcccc}
\hline & \multicolumn{2}{c}{ Low-rise building } & \multicolumn{2}{c}{ High-rise building } \\
\hline & $\mathrm{X}$ & $\mathrm{Y}$ & $\mathrm{X}$ & $\mathrm{Y}$ \\
\hline Max (m) & 1.174 & 1.231 & 3.179 & 5.254 \\
\hline Min (m) & 0.21 & 0.027 & 0.095 & 0.533 \\
\hline $\begin{array}{l}\text { Average } \\
\text { difference (m) }\end{array}$ & 0.567 & 0.527 & 1.189 & 2.798 \\
\hline Max (m) & 0.609 & 0.704 & 1.99 & 2.798 \\
\hline Min (m) & 0.006 & 0.002 & 0.203 & 0.078 \\
\hline $\begin{array}{l}\text { Average fitting } \\
\text { difference (m) }\end{array}$ & 0.226 & 0.242 & 0.9 & 1.095 \\
\hline
\end{tabular}

Table 6. Fitting Accuracy using the traditional method

The reason behind the considerable differences in the high building area $(0.9 \mathrm{~m}$ in the $\mathrm{X}$ direction and $1.1 \mathrm{~m}$ in the Y direction) is that the satellite image that was used was not a true Ortho image. Hence, the building's façade appeared and caused an error in calculating the difference between the roof and bottom coordinates for the building corners and affected all measurements on the roof corners.

To obtain the 2D Helmert transformation parameters, a shift to the centroid of each set of buildings was performed on the coordinates, because the transformation is very sensitive to any change in value of the rotation. Therefore, it was important to define different parameters in each zone. A total of six control points were selected in each area, with low and high buildings, to solve a set of 12 equations with four parameters.

Then, the parameters obtained were applied to other known corner coordinates extracted from the LiDAR point cloud to establish the goodness-of-fit of the data adjustment. The statistics results for the residual errors are shown in Table 7.

\begin{tabular}{lcccc}
\hline & \multicolumn{2}{c}{ Low-rise buildings } & \multicolumn{2}{c}{ High-rise buildings } \\
\cline { 2 - 5 } & $\mathrm{e}_{\mathrm{x}}$ & $\mathrm{e}_{\mathrm{y}}$ & $\mathrm{e}_{\mathrm{x}}$ & $\mathrm{e}_{\mathrm{y}}$ \\
\hline Max (m) & 0.480 & 0.670 & 0.476 & 0.782 \\
\hline Min (m) & 0.001 & 0.070 & 0.261 & 0.074 \\
\hline $\begin{array}{l}\text { Average } \\
(\mathbf{m})\end{array}$ & 0.196 & 0.125 & 0.357 & 0.578 \\
\hline
\end{tabular}

Table 7. Fitting Accuracy using the Helmert transformation method. Residual errors $\left(\mathbf{e}_{\mathrm{x}}, \mathbf{e}_{\mathrm{y}}\right)$.

As expected, since there were no true orthophotos, the disparity was greater in high-rise building areas, and as a result the map projection was greater in $\mathrm{Y}$ coordinates than in $\mathrm{X}$ in this area.

The second method, the Helmert transformation, offered a better fit than the average shift method. Moreover, it was faster to apply, since in the first method the shift for each building was computed individually.

\subsection{Costs/benefits analysis}

In this section we estimate the cost and time using mobile LiDAR instead of a traditional survey. This estimate gives capability indicators of MMS in terms of efficiency and accuracy compared with traditional and daily survey activities.

\subsubsection{The computational cost}

In order to analyse the benefit of the algorithm proposed in terms of computational cost three lineal zones o strips, with different length have been selected. The algorithm was run for each of these strips in a common desktop computer processor i5 and 16 GB DDR4-SDRAM. Table 8 shows the number of manholes for each one and the time spent to extract them. It can be realized that the computational time is not related to the number of points in the cloud. However, it is directly proportional to the number of manholes. Based on the results, it is possible to remark that the algorithm is fast for point clouds with tens of millions points. 


\begin{tabular}{|c|c|c|c|}
\hline \multicolumn{2}{|c|}{ Sample strip } & \multirow[b]{2}{*}{$\begin{array}{l}\text { Number of } \\
\text { Manhole }\end{array}$} & \multirow[b]{2}{*}{$\begin{array}{c}\text { Time to extract Manhole } \\
\text { (second) }\end{array}$} \\
\hline $\begin{array}{l}\text { Length } \\
(\mathrm{Km})\end{array}$ & $\begin{array}{l}\text { Point cloud size } \\
\text { (million of points) }\end{array}$ & & \\
\hline 0.2 & 39.8 & 59 & 73.75 \\
\hline 0.3 & 37.1 & 64 & 80.00 \\
\hline 0.5 & 51.5 & 73 & 91.25 \\
\hline
\end{tabular}

Table 8. Time to extract manholes in different sample strips

\subsubsection{Cost and Time Saving}

The MMS and proposed methodology gave a positive result in saving time, cost and effort. The estimated cost of using a traditional survey method including the system equipment, maintenance and manpower is 609,939 USD in the first year, as shown in the details in the following table. In the second year, the total cost is 201,498 USD, as the system's equipment should last 10 years. The cost of a LiDAR system with the same features is 473,000 USD.

The difference between using the LiDAR system to update the current basemap and using the traditional survey was analysed to calculate the difference in cost and time (Table 9). The following comparison shows the difference between a traditional survey and LiDAR in cost and time. Additionally, an MMS survey is safer to operate, especially in harsh and desert environments. The table below shows the cost of using the LiDAR system and the traditional survey system, including the manpower needed and all the equipment.

\begin{tabular}{lccccc}
\hline & \multicolumn{2}{c}{ Traditional Survey } & \multicolumn{2}{c}{ LiDAR Survey } \\
\hline Survey Features & $\begin{array}{l}\text { Quantit } \\
\mathbf{y}\end{array}$ & $\begin{array}{l}\text { Time } \\
\text { (hr) }\end{array}$ & Cost USD) & Time (hr) & Cost (USD) \\
\hline $\begin{array}{l}\text { Road centreline } \\
(\mathbf{k m})\end{array}$ & 18.5 & 88 & 91,491 & 8 & 71,069 \\
\hline Curb stone $(\mathbf{k m})$ & 37 & 176 & 182,982 & 16 & 142,137 \\
\hline Buildings & 131 & 23 & 91,491 & 2 & 71,069 \\
\hline Light poles & 277 & 25 & 30,497 & 2.5 & 23,690 \\
\hline Street sign & 377 & 30 & 60,994 & 3 & 47,379 \\
\hline Manhole & 1678 & 80 & 152,485 & 7 & 118,448 \\
\hline Total & & 422 & $\mathbf{6 0 9 , 9 3 9}$ & 38.5 & $\mathbf{4 7 3 , 7 9 2}$ \\
\hline
\end{tabular}

Table 9. Comparison between the traditional survey and LiDAR survey in cost and time

The time spent surveying the features under study using the traditional survey methods was 422 hours in the study area (Table 9), while the surveying time for the same features in the same area was 38.5 hours (including field work, data transfer, data processing and extraction process).

After analysing time and cost differences, it was clear that the LiDAR system saved $22 \%$ of the surveying cost (in the first year) and $91 \%$ of the time needed to survey the same area.

\section{CONCLUSIONS}

In this study, we propose a method to extract elements from the 3D model obtained automatically from an MMS survey. The algorithms for the feature extraction process applied to street furniture in Abu Dhabi had a high success rate, but this rate varied from one zone to another depending on the urban pattern. The worst rate was obtained for the same features in peri-urban areas (Area 3), due to high vegetation. Manholes were detected with a successful extraction of around $98 \%$. Generally, the best percentages were achieved in Area 1 , as it had neither high buildings that block satellite signals nor vegetation areas. 
Despite the existence of high buildings in area 2, the detection rate for light poles and street signs was best (at $100 \%$ ) both in this area and in the area of low buildings (Area 1).

The proposed manhole extraction process fills the void that currently exists with commercial software, and it speeds up the data processing and manhole extraction (an average of 1.25 seconds per manhole) with a good percentage of completeness and correctness, around 97 and $98 \%$ respectively. The parameters used in this study are easy to adapt to manhole's cover with different material and rectangular or circular geometry for whatever urban area using as parameters the intensity range and size. Moreover, the ranges of intensity values adopted for the manholes of Abu Dhabi may be directly used in extracting steel manholes for other cities

During the study, there were some limitations to detecting manholes automatically using the proposed algorithm. These limitations were due to changes in the perception of manhole shape resulting from dust and car movement. In future studies, the algorithm could be enhanced to be more efficient by adding intensity parameters for dust to separate it and then determine new values of manhole intensity.

The building detection percentage was similar in all areas and was the lowest of all the elements. To complete the buildings, additional information must be obtained from a different source. A satellite image provides addition information to mobile LiDAR, since the satellite dataset includes building roofs and the entire canopy. However, satellite images are less accurate than MMS, due to the long distance between the sensor and objects, and the complexity of the sensor calibration parameters. From the two methods used in the adjustment of the buildings, it has been proven that the 2D Helmert transformation offers a better, faster outcome than adjusting each building individually. This transformation must be computed and applied in different sectors where the buildings have the same height and orientation, since the transformation is sensitive to them, as mentioned above.

On average, the positioning accuracy of the navigation data (trajectory) was below $4 \mathrm{~cm}$ while the accuracy of the processed point cloud was below $2 \mathrm{~cm}$, which led to an accuracy of 5-10 $\mathrm{cm}$ in the feature extraction process. A satellite image can be used to obtain missing data (as some building corners) that are outside the LiDAR camera view, with an accuracy of $4 \mathrm{~cm}$ on average.

Regarding the geometric quality of the new map, it was found that the system produces results that are within the tolerances for this scale $(15 \mathrm{~cm})$, i.e. a scale of 1:1000, in all areas regardless of the urban pattern. For all elements, the average discrepancy in position, considering as a ground truth the current map made with more expensive techniques, is less than $2 \mathrm{~cm}$ in most elements. Only some maximum values were found as outliers in the area of high buildings, where the GNSS signal was obstructed and therefore the precision of the vehicle's trajectory decreases.

Regarding the findings, in this case, where aerial photogrammetry is not an option, the proposed methodology using remote sensing techniques is more effective than conventional methods of surveying, since it allows us to obtain basemaps in less time for urban applications. The LiDAR system saves around $22 \%$ of the cost and $91 \%$ of the time compared to the traditional survey method.

\section{REFERENCES}

[1] C. Steinitz, A framework for geodesign: Changing geography by design, CA: ESRI Press, Redlands, 2012, pp 8-10, ISBN: 9781589483330.

[2] P. Pelzer, M. Brömmelstroet, S. Geertman, Geodesign in practice: What about the urban designers?, in: D. Lee, E. Dias, H. Scholten (Eds.), Geodesign by Integrating Design and Geospatial Sciences. GeoJournal Library, Vol. 111, Springer, Cham, 2014, pp 331-344, Online ISBN 978-3-319-082998, https://doi.org/10.1007/978-3-319-08299-8 21.

[3] S. M. Ervin, Technology in geodesign, Landscape and Urban Planning 156 (2016) 12-16, https://doi.org/10.1016/j.landurbplan.2016.09.010.

[4] T. Hermosilla, L. A. Ruiz, J. A. Recio, M. Cambra-López, Assessing contextual descriptive features for plot-based classification of urban areas, Landscape and Urban Planning 106 (2012) 124-137, https://doi.org/10.1016/j.landurbplan.2012.02.008. 
[5] C. San-Antonio-Gómez, C. Velilla, F. Manzano-Agugliaro, Urban and landscape changes through historical maps: The real sitio of Aranjuez (1775-2005), a case study, Computers, Environment and Urban Systems 44 (2014) 47-58, https://doi.org/10.1016/j.compenvurbsys.2013.12.001.

[6] J. Kaňuk, M. Gallay, J. Hofierka, Generating time series of virtual 3-D city models using a retrospective approach, Landscape and Urban Planning 139 (2015) 40-53, https://doi.org/doi:10.1016/j.landurbplan.2015.02.015.

[7] T. M. Quack, M. Reiter, D. Abel, Digital map generation and localization for vehicles in urban intersections using LiDAR and GNSS data, IFAC-PapersOnLine 50 (2017) 251-257, https://doi.org/10.1016/j.ifacol.2017.08.042.

[8] C. Heipke, P. A. Woodsford, M. Gerke, Updating geospatial databases from images, in: Proc. Advances in Photogrammetry, Remote Sensing and Spatial Information Sciences: 2008 ISPRS Congress Book, E. Baltsavias, Z. Li, J. Chen (Eds.), Vol. 7, CRC Press, London, 2008, pp. 355363, ISBN 978-0-203-88844-5.

[9] Z. Li, J. Chen, E. Baltsavias, Advances in photogrammetry, Remote Sensing and Spatial Information Sciences, in: Proc. 2008 ISPRS congress, CRC Press, London, 2008.

[10] M. A. Núñez-Andrés, F. Buill Pozuelo, Evolution of the architectural and heritage

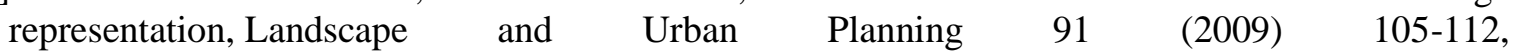
https://doi.org/10.1016/j.landurbplan.2008.12.006.

[11] E. P. Baltsavias, A comparison between photogrammetry and laser scanning, ISPRS Journal of Photogrammetry and Remote Sensing 54 (1999) 83-94, https://doi.org/10.1016/S09242716(99)00014-3.

[12] S. Ibrahim, D. Lichti, Curb-based street floor extraction from mobile terrestrial lidar point cloud, ISPRS-International Archives of the Photogrammetry, Remote Sensing and Spatial Information Sciences XXXIX-B5 (2012) 193-198, https://doi.org/10.5194/isprsarchives-xxxix-b5193-2012.

[13] B. Rodríguez-Cuenca, S. García-Cortés, C. Ordóñez, M. C. Alonso, Automatic detection and classification of pole-like objects in urban point cloud data using an anomaly detection algorithm, Remote Sensing 7 (10) (2015) 12680-12703, https://doi.org/10.3390/rs71012680.

[14] C. Cabo A. Kukko, S. García-Cortés, H. Kaartinen, J. Hyyppä, C. Ordoñez, An algorithm for automatic road asphalt edge delineation from mobile laser scanner data using the line clouds concept, Remote Sensing 8 (9) (2016) 740-760, https://doi.org/10.3390/rs8090740.

[15] B. Rodríguez-Cuenca, S. García-Cortés, C. Ordóñez, M. C. Alonso, An approach to detect and delineate street curbs from MLS 3D point cloud data, Automation in Construction 51 (2015) 103112, https://doi.org/10.1016/j.autcon.2014.12.009.

[16] S. Hofmann, C. Brenner, Quality assessment of automatically generated feature maps for future driver assistance systems, in: Proc.17th ACM International Symposium on Advances in Geographic Information Systems, 2009, pp.500-503, https://doi.org/10.1145/1653771.1653854.

[17] A. Jaakkola, J. Hyyppä, A. Kukko, X. Yu, H. Kaartinen, M. Lehtomäki, Y. Lin, A low-cost multi-sensoral mobile mapping system and its feasibility for tree measurements, ISPRS Journal of Photogrammetry and Remote Sensing 65 (6) (2010) 514-522, https://doi.org/10.1016/j.isprsjprs.2010.08.002.

[18] M. Lehtomäki, A. Jaakkola, J. Hyyppä, A. Kukko, H. Kaartinen, Detection of vertical pole-like objects in a road environment using vehicle-based laser scanning data, Remote Sensing 2 (3) (2010) 641-664, https://doi.org/10.3390/rs2030641.

[19] M. Yadav, A. K. Singh, B. Lohani, Extraction of road surface from mobile LiDAR data of complex road environment, International Journal of Remote Sensing 38 (16) (2017) 4655-4682, https://doi.org/10.1080/01431161.2017.1320451.

[20] M. Cramer, D. Stallmann, On the use of GPS/inertial exterior orientation parameters in airborne photogrammetry, in: Proc. Workshop, Integrated sensor orientation, test report and workshop proceedings, Vol. 43, Official Publication- OEEPE , Hannover, 2001, pp. 109-122, ISBN 3898888649.

[21] B. Yang, Z. Wei, Q. Li, J. Li, Automated extraction of street-scene objects from mobile lidar point clouds, International Journal of Remote Sensing 33 (18) (2012) 5839-5861, https://doi.org/10.1080/01431161.2012.674229.

[22] W. Ostrowski, Accuracy of measurements in oblique aerial foe urban environmental, ISPRSInternational Archives of the Photogrammetry, Remote Sensing and Spatial Information Sciences XLII-2/W2 (2016) 79-85, https://doi.org/10.5194/isprs-archives-XLII-2-W2-79-2016. 
[23] D. Chen, R. Wang, J. Peethambaran, Topologically aware building rooftop reconstruction from airborne laser scanning point clouds, IEEE Transactions on Geoscience and Remote Sensing 55 (2017) 7032-7052, https://doi.org/10.1109/TGRS.2017.2738439.

[24] Y. Sun, H. Sun, L. Yan, S. Fan, R. Chen, RBA, Reduced Bundle Adjustment for oblique aerial photogrammetry, ISPRS Journal of Photogrammetry and Remote Sensing 121 (2016) 128-142, https://doi.org/10.1016/j.isprsjprs.2016.09.005.

[25] F. Nex, F. Remondino, UAV for 3D mapping applications, Applied Geomatics 6 (1) (2014) 115, https://doi.org/10.1007/s12518-013-0120-x.

[26] A.M. Dolan, R.M. Thompson, II. Integration of drones into domestic airspace: Selected Legal Issues, Washington D.C. pp. 107-137, https://digital.library.unt.edu/ark:/67531/metadc462809/ (2013), Accessed date: 12 December 2019.

[27] C. Stöcker, R. Bennett, F. Nex, M. Gerke, J. Zevenbergen, Review of the current state of UAV regulations, Remote Sensing 9 (5) (2017) 459-475, https://doi.org/10.3390/rs9050459.

[28] F. Remondino, M. G. Spera, E. Nocerino, F. Menna, F. Nex, State of the art in high density image matching, Photogrammetric Record 29 (146) (2014) 144-166, https://doi.org/10.1111/phor.12063.

[29] A. Alexandrov, T. Hristova, K. Ivanova, M. Koeva, T. Madzharova, V. Petrova, Application of QuickBird satellite imagery for updating cadastral information, ISPRS-International Archives of the Photogrammetry, Remote Sensing and Spatial Information Sciences XXXV Part B2 (2004) 386-391.

[30] Z. Ali, A. Tuladhar, J. Zevenbergen, An integrated approach for updating cadastral maps in Pakistan using satellite remote sensing data, International Journal of Applied Earth Observation and Geoinformation 18 (2012) 386-398, https://doi.org/10.1016/j.jag.2012.03.008.

[31] A. Gruen, E. Baltsavias, O. Henricsson, (Eds), Automatic extraction of man-made objects from aerial and space images (II), Birkhauser, Boston, 1998, pp. 43-52, eBook ISBN978-3-0348-89063, https://doi.org/10.1007/978-3-0348-8906-3.

[32] M. M. Awad, A morphological model for extracting road networks from high-resolution satellite images, Journal of Engineering 2013 (2013) 1-9, http://dx.doi.org/10.1155/2013/243021.

[33] M. Gianinetto, Updating large scale topographic databases in italian urban areas with submeter QuickBird images, International Journal of Navigation and Observation 2008 (2008) 1-9, http://dx.doi.org/10.1155/2008/725429.

[34] I. Grinias, C. Panagiotakis, G. Tziritas, MRF-based segmentation and unsupervised classification for building and road detection in peri-urban areas of high-resolution satellite images, ISPRS Journal of Photogrammetry and Remote Sensing 122 (2016) 145-166, https://doi.org/10.1016/j.isprsjprs.2016.10.010.

[35] G. Gräfe, High precision kinematic surveying with laser scanners, Journal of Applied Geodesy 1 (4) (2007) 185-199, https://doi.org/10.1515/jag.2007.021.

[36] K. Qiu, K. Sun, K. Ding, Z. Shu, A fast and robust algorithm for road edges extraction from Lidar data, ISPRS-International Archives of the Photogrammetry, Remote Sensing and Spatial Information Sciences XLI-B5 (2016) 693-698, https://doi.org/10.5194/isprs-archives-XLI-B5693-2016.

[37] H. Guan, J. Li, S. Cao, Y. Yu, Use of mobile LiDAR in road information inventory: A review, International Journal of Image and Data Fusion 7 (3) (2016) 219-242, https://doi.org/10.1080/19479832.2016.1188860.

[38] S. Pu, M. Rutzinger, G. Vosselman, S. Oude Elberink, Recognizing basic structures from mobile laser scanning data for road inventory studies, ISPRS Journal of Photogrammetry and Remote Sensing 66 (6) (2011) S28-S39, https://doi.org/10.1016/j.isprsjprs.2011.08.006.

[39] L. Ru-Fei, M. Tian, R. Liu, and X. Lu, Ground point filtering method of vehicle-borne laser point cloud in urban street, Computer Modelling and New Technologies 18 (3) (2014) 188-192.

[40] Y. Zhou, D. Wang, X. Xie, Y. Ren, G. Li, Y. Deng, Z. Wang, A fast and accurate segmentation method for ordered LiDAR point cloud of large-scale scenes, IEEE Geoscience and Remote Sensing Letters 11 (11) (2014) 1981-1985, https://doi.org/10.1109/LGRS.2014.2316009.

[41] Y. Yu, J. Li, H. Guan, C. Wang, J. Yu, Semiautomated extraction of street light poles from mobile LiDAR point-clouds, IEEE Transactions on Geoscience and Remote Sensing 53 (3) (2015) 1374-1386, https://doi.org/10.1109/TGRS.2014.2338915. 
[42] Y. Chen, H. J. Zhao, R. Shibasaki, A mobile system combining laser scanners and cameras for urban spatial objects extraction, in: Proc. International Conference on Machine Learning and Cybernetics, vol. 3, 2007, pp. 1729-1733, https://doi.org/10.1109/ICMLC.2007.4370426.

[43] M. Javanmardi, E. Javanmardi, Y. Gu, S. Kamijo, Towards high-definition 3D urban mapping: Road feature-based registration of mobile mapping systems and aerial imagery, Remote Sensing 9 (10) (2017) 975-1005, https://doi.org/10.3390/rs9100975.

[44] H. Guan, Y. Yu, Z. Ji, J. Li, Q. Zhang, Deep learning-based tree classification using mobile LiDAR data, Remote Sensing Letters 6 (11) (2015) 864-873, https://doi.org/10.1080/2150704X.2015.1088668.

[45] B. Commandre, D. En-Nejjary, L. Pibre, M. Chaumont, C. Delenne, N. Chahinian., Manhole cover localization in aerial images with a deep learning approach, ISPRS-International Archives of the Photogrammetry, Remote Sensing and Spatial Information Sciences XLII-1-W1(42) (2017) 333-338, https://doi.org/10.5194/isprs-archives-XLII-1-W1-333-2017.

[46] R. Timofte, L. Van Gool, Multi view manhole detection, recognition and 3D localization, in: Proc. IEEE International Conference on Computer Vision, 2011, pp. 188-195, https://doi.org/10.1109/ICCVW.2011.6130242.

[47] W. Zhang, Lidar-based road and road edge detection, in: Proc. IEEE Intelligent Vehicles Symposium, 2010, pp. 845-848, https://doi.org/10.1109/IVS.2010.5548134.

[48] Y. Yu, J. Li, H. Guan, C. Wang, J. Yu, Automated detection of road manhole and sewer well covers from mobile LiDAR point clouds, IEEE Geoscience and Remote Sensing Letters 11 (9) (2014) 1549-1553, https://doi.org/10.1109/LGRS.2014.2301195.

[49] E. Maltezos, A. Doulamis, N. Doulamis, C. Ioannidis, Building extraction from LiDAR data applying deep convolutional neural networks, IEEE Geoscience and Remote Sensing Letters 16 (1) (2019) 155-159, https://doi.org/10.1109/LGRS.2018.2867736.

[50] P. Li, S. Jiang, X. Wang, J. Zhang, Building extraction using lidar data and very high resolution image over complex urban area, in: Proc. International Geoscience and Remote Sensing Symposium (IGARSS), 2013, pp. 4253-4256, https://doi.org/10.1109/IGARSS.2013.6723773.

[51] D. K. San, M. Turker, Building extraction from high resolution satellite images using Hough transform, ISPRS-International Archives of the Photogrammetry, Remote Sensing and Spatial Information Sciences XXXVIII (8) (2010) 1063-1068.

[52] R. Alshehhi, P. R. Marpu, W. L. Woon, M. D. Mura, Simultaneous extraction of roads and buildings in remote sensing imagery with convolutional neural networks, ISPRS Journal of $\begin{array}{lllll}\text { Photogrammetry and Remote } & 130 \text { (2017) }\end{array}$ https://doi.org/10.1016/j.isprsjprs.2017.05.002.

[53] Optech, Lynx SG Mobile Mapper, Summary Specification Sheet Available, http://www.teledyneoptech.com/wp-content/uploads/Lynx-Specsheet-SG-160404.pdf, (2017), Accessed date: 4 July 2018.

[54] I. Puente, H. González-Jorge, J. Martínez-Sánchez, P. Arias, Review of mobile mapping and surveying technologies. Measurement, Journal of the International Measurement Confederation 46 (7) (2013) 2127-2145, https://doi.org/10.1016/j.measurement.2013.03.006.

[55] Y. Yu, H. Guan, Z. Ji, Automated detection of urban road manhole covers using mobile laser scanning data, IEEE Transactions on Intelligent Transportation Systems 16 (6) (2015) 3258-3269, https://doi.org/10.1109/TITS.2015.2413812. 